\title{
Potential Tamoxifen Repurposing to Combat Infections by Multidrug-Resistant Gram-Negative Bacilli
}

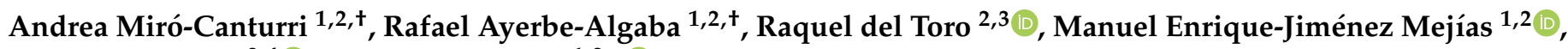 \\ Jerónimo Pachón ${ }^{2,4}$ and Younes Smani ${ }^{1,2, * \mathbb{D}}$ \\ 1 Clinical Unit of Infectious Diseases, Microbiology and Preventive Medicine, \\ University Hospital Virgen del Rocío, 41013 Seville, Spain; amirocan93@gmail.com (A.M.-C.); \\ ayerberafael@gmail.com (R.A.-A.); mej-mejias@telefonica.net (M.E.-J.M.) \\ 2 Institute of Biomedicine of Seville (IBiS), University Hospital Virgen del Rocío, CSIC, University of Seville, \\ 41013 Seville, Spain; rdeltoro-ibis@us.es (R.d.T.); pachon@us.es (J.P.) \\ 3 Department of Medical Physiology and Biophysics, Institute of Biomedicine of Seville, University of Seville, \\ 41009 Seville, Spain \\ 4 Department of Medicine, University of Seville, 41009 Seville, Spain \\ * Correspondence: ysmani-ibis@us.es; Tel.: +34-955-923-100 \\ + These authors contributed equally to this work.
}

\section{check for} updates

Citation: Miró-Canturri, A.; Ayerbe-Algaba, R.; del Toro, R.; Mejías, M.E.-J.; Pachón, J.; Smani, Y. Potential Tamoxifen Repurposing to Combat Infections by Multidrug-Resistant Gram-Negative Bacilli. Pharmaceuticals 2021, 14, 507. https://doi.org/10.3390/ ph14060507

Academic Editor: Maria Emília de Sousa

Received: 5 May 2021

Accepted: 21 May 2021

Published: 26 May 2021

Publisher's Note: MDPI stays neutral with regard to jurisdictional claims in published maps and institutional affiliations.

Copyright: (c) 2021 by the authors. Licensee MDPI, Basel, Switzerland. This article is an open access article distributed under the terms and conditions of the Creative Commons Attribution (CC BY) license (https:/ / creativecommons.org/licenses/by/ $4.0 /)$.

\begin{abstract}
The development of new strategic therapies for multidrug-resistant bacteria, like the use of non-antimicrobial approaches and/or drugs repurposed to be used as monotherapies or in combination with clinically relevant antibiotics, has become urgent. A therapeutic alternative for infections by multidrug-resistant Gram-negative bacilli (MDR-GNB) is immune system modulation to improve the infection clearance. We showed that immunocompetent mice pretreated with tamoxifen at $80 \mathrm{mg} / \mathrm{kg} / \mathrm{d}$ for three days and infected with Acinetobacter baumannii, Pseudomonas aeruginosa, or Escherichia coli in peritoneal sepsis models showed reduced release of the monocyte chemotactic protein-1 (MCP-1) and its signaling pathway interleukin-18 (IL-18), and phosphorylated extracellular signal-regulated kinase 1/2 (ERK1/2). This reduction of MCP-1 induced the reduction of migration of inflammatory monocytes and neutrophils from the bone marrow to the blood. Indeed, pretreatment with tamoxifen in murine peritoneal sepsis models reduced the bacterial load in tissues and blood, and increased mice survival from $0 \%$ to $60-100 \%$. Together, these data show that tamoxifen presents therapeutic efficacy against MDR A. baumannii, P. aeruginosa, and E. coli in experimental models of infection and may be a new candidate to be repurposed as a treatment for GNB infections.
\end{abstract}

Keywords: repurposing drug; tamoxifen; bacteria; infection; animal model; immune system

\section{Introduction}

Infections caused by Gram-negative bacilli (GNB) such as Acinetobacter baumannii, Pseudomonas aeruginosa, and Escherichia coli represent an increasing worldwide problem.

Sepsis is a major cause of mortality in acute infections, characterized by a systemic inflammatory response syndrome caused by them [1,2]. In the United States the incidence of sepsis was increased from 50-95 to 535 cases per 100,000 inhabitants between 2003 and 2015 [3,4]. Despite the correct management that includes adequate resuscitation and early antibiotic treatment, mortality in patients with sepsis and septic shock is very high, ranging between $25 \%$ and $70 \%[2,5]$.

In 2017, the World Health Organization listed these pathogens as the first antibioticresistant "priority pathogens" that pose the greatest threat to human health. There is, therefore, an urgent need to find new antimicrobial agents against extensive and pan-drugresistant GNB. Two key approaches can help alleviate the problem of antibiotic resistance, first by targeting the bacterial virulence factors without inhibiting bacterial growth, which can slow the development of drug resistance by reducing the selective pressure on the 
bacteria $[6,7]$ and, secondly, by the modulation/regulation of the immune system response to improve the infection development $[8,9]$. In this context, some studies focused on the stimulation of the immune system to treat bacterial infections using molecules including lysophosphatidylcholine as monotherapy and as adjuvant for the antimicrobial treatment $[8,10,11]$ or $3^{\prime}-5^{\prime}$-cyclic diguanylic acid (c-di-GMP), which increase neutrophils protecting against $A$. baumannii infection [12].

Inflammatory monocytes and neutrophils derived from bone marrow are important cellular mediators of the innate immune response against bacterial infections. During the early stages of a bacterial infection, both cell populations migrate from the bone marrow to the bloodstream and, subsequently, to the sites of infection $[13,14]$. This migration is partially regulated by the monocyte chemotactic protein-1 (MCP-1), whose expression is increased in bone marrow mesenchymal cells in response to circulating Toll-like receptor ligands and results in the mobilization of inflammatory monocytes [15]. It is well established that MCP-1 release is controlled by interleukin-18 (IL-18) and extracellular signal-regulated kinase 1/2 (ERK1/2) [16], and the levels of MCP-1 are higher in patients with sepsis, septic shock, and pneumonia $[17,18]$.

It has been well documented that anticancer drugs like tamoxifen can modify the immune response by regulating cytokine release [19]. Mechanistically, tamoxifen has been reported to reduce $\mathrm{MCP}-1$ transcription and expression in human coronary artery endothelial cells and endometrial cancer cells, respectively [20,21]. As MCP-1 is involved in the immune cells' migration, it may be hypothesized that an undiscovered connection between MCP-1 release and immune cells' migration after bacterial infection and treatment with tamoxifen is present.

In this study, we report that tamoxifen downregulates the expression of MCP-1, impairing the migration of bone marrow-derived cells to the bloodstream induced by A. baumannii, P. aeruginosa, and E. coli and, consequently, modulating the inflammatory response. In a murine peritoneal sepsis model, we observed that tamoxifen decreased the development of infection by these pathogens, lowering their concentrations in tissues and blood and increasing mice's survival.

\section{Results}

2.1. Bone Marrow Immune Cells Migrate in Response to Monocyte Chemotactic Protein-1 (MCP-1) and Interleukin-18 (IL-18) during Bacterial Infection

To determine whether bacterial infection influences circulating immune cells from the bone marrow in response to MCP-1 and IL-18, a MCP-1 controller [16], we intraperitoneally (ip.) administered A. baumannii, P. aeruginosa, and E. coli to mice and measured the proportions of myeloid cells CD11b+, inflammatory monocytes CD11b+Ly6Chi, and neutrophils CD11b+Ly6G+. After $24 \mathrm{~h}$ of A. baumannii infection, the percentages of immune cells (myeloid cells, inflammatory monocytes, and neutrophils) were decreased in bone marrow and were increased in blood (Figure 1A-C). The same results were observed when mice were infected with P. aeruginosa and E. coli (Figure 1A-C). In the spleen, the percentages of these immune cells, from a total of $1.6 \times 10^{6}$ cells $/ \mathrm{mL}$, were decreased less after infection with A. baumannii, P. aeruginosa, and E. coli for $24 \mathrm{~h}$ (Table S1); indicating that the increase of circulating monocytes and neutrophils did not proceed from the splenic reservoir [22,23]. Interestingly, no significant differences in the population of lymphocytes B and T CD4+ and CD8+ were observed between non-infected and infected mice in the bone marrow, spleen, and blood $24 \mathrm{~h}$ post-bacterial infection, except for the bone marrow lymphocytes CD8+ of mice infected with P. aeruginosa (Figure S1). 
A

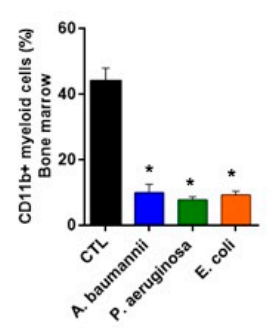

B
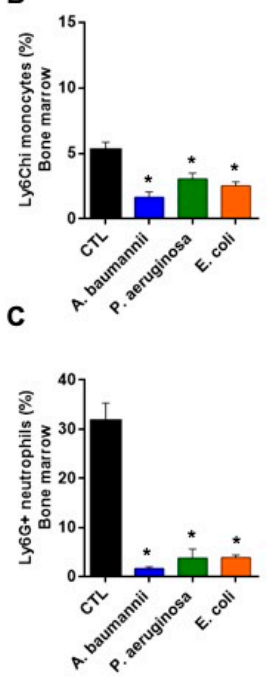

D
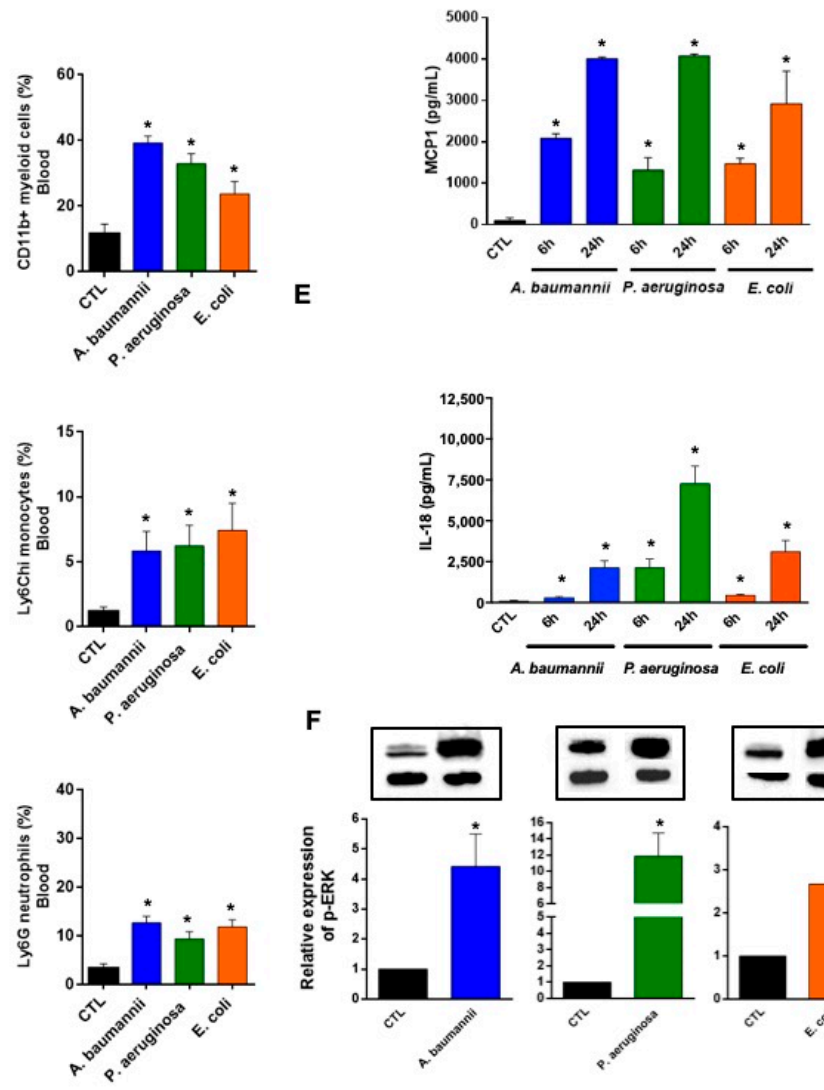

F
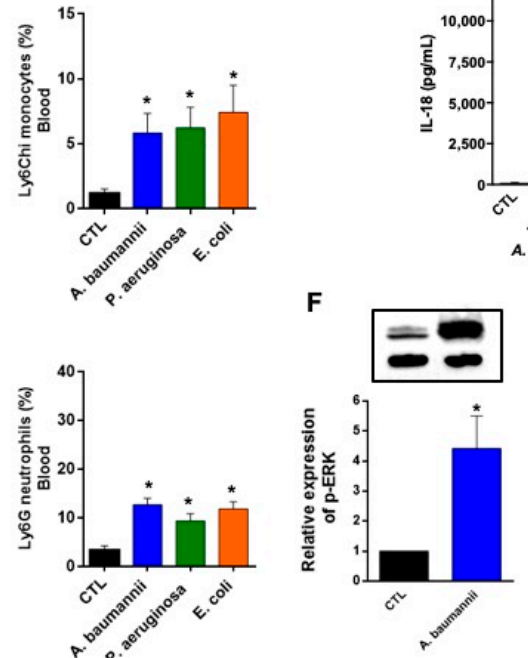
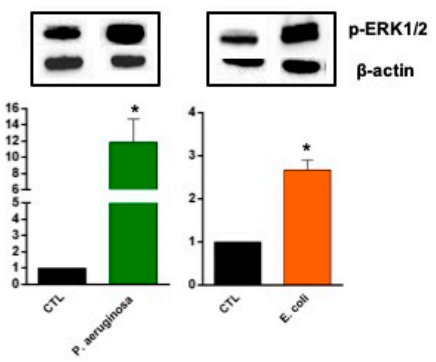

Figure 1. Bone marrow immune cells' migration to the blood in response to monocyte chemotactic protein-1 (MCP-1) and interleukin-18 (IL-18) during bacterial infection. (A) Myeloid cells, (B) inflammatory monocytes, and (C) neutrophils were identified as CD11b+, CD11b+Ly6Chi, and CD11b+Ly6G+, respectively, by flow cytometry in the bone marrow and blood of mice infected with MLD100 of A. baumannii ATCC17978, P. aeruginosa PAO1, or E. coli ATCC25922 strains for $24 \mathrm{~h}$. (D,E) Serum MCP-1 and IL-18 levels (enzyme-linked immunosorbent assays (ELISAs)), 6 and $24 \mathrm{~h}$ post-infection, in mice infected with minimal lethal dose 100 (MLD100) of A. baumannii ATCC17978, P. aeruginosa PAO1, or E. coli ATCC25922 strains. (F) RAW 264.7 cells were infected with $A$. baumannii ATCC17978, P. aeruginosa PAO1, or E. coli ATCC25922 strains for $2 \mathrm{~h}$ and proteins were collected for phospho-p44/42 Mitogen-Activated Protein Kinases (extracellular signal-regulated kinase 1/2 $($ Erk1/2)) and $\beta$-actin immunoblotting. Data are representative of six mice per group, and expressed as mean \pm standard error of the mean (SEM). ${ }^{*} p<0.05$ : infected vs. control (CTL). CTL: non-infected mice, \%: the percentage of myeloid cells, inflammatory monocytes and neutrophils from total cells in bone marrow or blood.

A paradigm widely accepted is the formation of chemokine gradients to guide inflammatory cells to the sites of infection [24]. Among them, MCP-1 has been shown to be involved in the migration of immune cells from the bone marrow to the bloodstream after binding to the CCR2 receptor [25]. As shown in Figure 1D, mice infected with A. baumannii, $P$. aeruginosa, and $E$. coli for 6 and $24 \mathrm{~h}$ increased the release of MCP-1 in mice serum significantly and progressively (between 1000 and $4000 \mu \mathrm{g} / \mathrm{mL}$ ). It is well known that MCP-1 release is controlled by IL-18 and ERK1/2 [16]. Consequently, the levels of IL-18 in mice serum gradually increased 6 and $24 \mathrm{~h}$ after infection with A. baumannii, P. aeruginosa, and E. coli. The IL-18 levels at $24 \mathrm{~h}$ were $2144 \pm 408.1 \mu \mathrm{g} / \mathrm{mL}, 7286 \pm 1056 \mu \mathrm{g} / \mathrm{mL}$, and $3124 \pm 671.3 \mu \mathrm{g} / \mathrm{mL}$, respectively (Figure 1E). Moreover, ERK1/2 was phosphorylated $2 \mathrm{~h}$ after infection of the RAW 264.7 macrophage cell line in vitro with $A$. baumannii, $P$. aeruginosa, and E. coli, defining the activation of kinase response to these pathogens (Figure 1F). 
To determine whether MCP-1 is involved in the migration of inflammatory monocytes and neutrophils from bone marrow to blood, wild-type (WT) mice and mice lacking the MCP-1 protein (MCP-1 knockout (KO) mice) were infected with A. baumannii, $P$. aeruginosa, and E. coli. First, we detected MCP-1 release only in WT mice (Figure 2A). Importantly, the infection of MCP-1 KO mice with these pathogens showed that the migration of inflammatory monocytes and neutrophils from the bone marrow to the blood (Figure $2 \mathrm{~B}, \mathrm{C})$ causes a reduction of $6.76 \pm 1.55 \%$ to $2.17 \pm 1.14 \%(p=0.049)$ and from $12.67 \pm 1.37 \%$ to $4.13 \pm 0.99 \%(p=0.043)$, respectively, for $A$. baumannii infection. Similar results were observed when MCP-1 KO mice were infected with P. aeruginosa and E. coli strains (Figure 2B,C). Non-infected WT and MCP-1 KO mice presented similar inflammatory monocytes and neutrophil proportions in the bone marrow $(p=0.85$ and $p=0.71)$ and in blood ( $p=0.34$ for both cells), indicating that the lack of MCP-1 did not affect the migration of these cells from the bone marrow in basal conditions (Figure 2B,C). These data suggest that MCP-1 is involved in the traffic of immune cells from the bone marrow to the blood after infection with A. baumannii, P. aeruginosa, and E. coli.

A

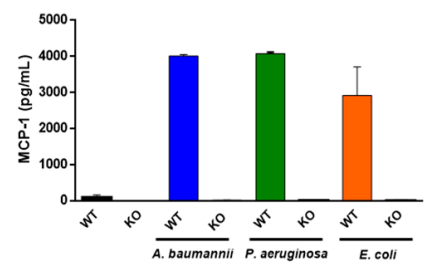

B
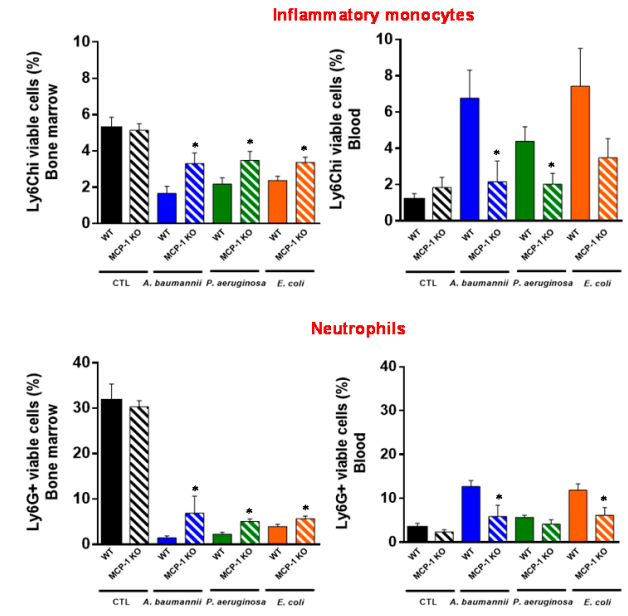

Figure 2. Role of MCP-1 in the bone marrow immune cells' migration to the blood during bacterial infection. (A) Wild-type (WT) and MCP-1 knockout (KO) mice were infected with minimal lethal dose 100 (MLD100) of A. baumannii ATCC17978, P. aeruginosa PAO1, or E. coli ATCC25922 strains. Twenty-four hours post-infection, serum was harvested for MCP-1 ELISAs. (B) Inflammatory monocytes and (C) neutrophils were identified as CD11b+Ly6Chi and CD11b+Ly6G+ by flow cytometry, respectively, in the bone marrow and blood of wild-type and MCP-1 KO mice infected with MLD100 of A. baumannii ATCC17978, P. aeruginosa PAO1, or E. coli ATCC25922 strains for $24 \mathrm{~h}$. Data are representative of six mice per group, and expressed as mean $\pm \mathrm{SEM}$. ${ }^{*} p<0.05$ : WT vs. MCP-1 KO. WT: wild-type, MCP-1 KO: mice lacking MCP-1, CTL: non-infected mice, \%: the percentage of inflammatory monocytes and neutrophils from total cells in bone marrow or blood.

\subsection{Tamoxifen Impairs the Migration of Immune Cells from Bone Marrow to Blood}

In order to study whether tamoxifen can modulate the inflammation generated by bacterial infections, we treated the RAW 264.7 macrophage cell line with tamoxifen for $24 \mathrm{~h}$ and infected the cells with A. baumannii, P. aeruginosa, or E. coli for $2 \mathrm{~h}$. After this incubation, we determined the secretion of MCP-1 in the macrophage cells supernatant (enzyme-linked immunosorbent assay (ELISA)) and the phosphorylation of ERK in the macrophage cells by Western blot. The treatment with tamoxifen decreased the release of MCP-1 and the phosphorylation of ERK1/2 in macrophages infected with these pathogens, compared to macrophages without tamoxifen treatment (Figure 3A,B). To confirm these data in vivo, mice were treated ip. with three doses of $80 \mathrm{mg} / \mathrm{kg} / \mathrm{d}$ of tamoxifen before the bacterial infection. Serum was collected 6 and $24 \mathrm{~h}$ post-bacterial infection. Figure $3 \mathrm{C}$ reveals that treatment with tamoxifen reduced MCP-1 levels when compared with A. baumannii-, P. aeruginosa-, or E. coli-infected and not treated groups. It is worth highlighting that IL-18 
levels were also reduced after tamoxifen treatment of mice infected with A. baumannii, P. aeruginosa, and E. coli (Figure 3D).

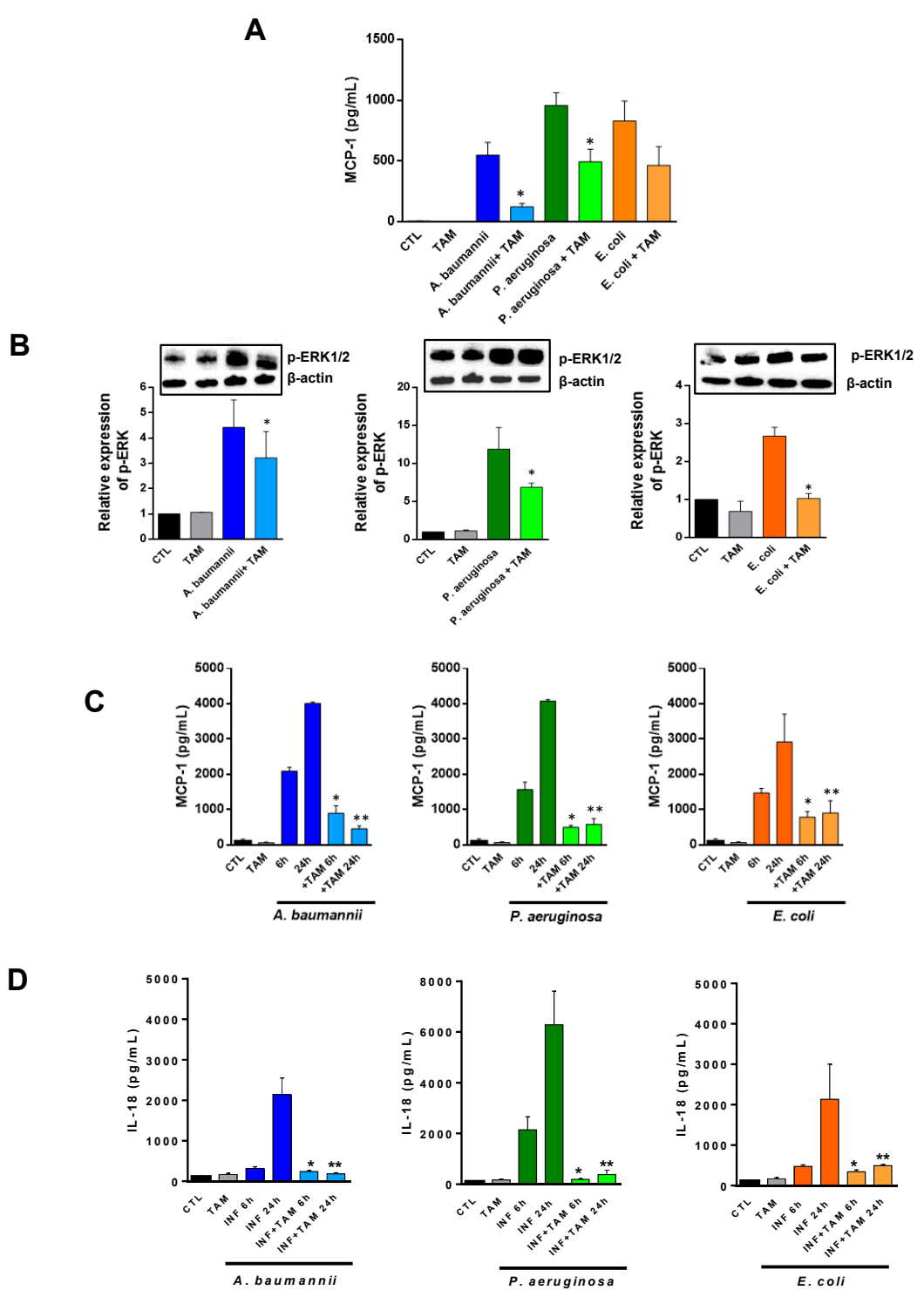

Figure 3. Tamoxifen reduces, after bacterial infection, the release of MCP-1 and IL-18 in vitro and in vivo, and ERK phosphorylation in vitro. (A,B) RAW 264.7 cells were treated with $2.5 \mathrm{mg} / \mathrm{L}$ of tamoxifen for $24 \mathrm{~h}$ and infected with A. baumannii ATCC17978, P. aeruginosa PAO1, or E. coli ATCC25922 strains for $2 \mathrm{~h}$. MCP-1 levels and ERK-phosphorylation were determined by ELISA and immunoblotting assays, respectively. Data are representative of three independent experiments, and expressed as mean \pm SEM. (C,D) Mice received firstly tamoxifen $(80 \mathrm{mg} / \mathrm{kg} / \mathrm{d}$, for three days), followed by infection with a minimal lethal dose 100 (MLD100) of A. baumannii ATCC17978, P. aeruginosa PAO1, or E. coli ATCC25922 strains. At 6 and 24 h post-infection, serum was harvested for MCP-1 and IL-18 ELISA assays. Data are representative of six mice per group and are expressed as mean \pm SEM. ${ }^{*} p<0.05$ : treated vs. INF, ${ }^{* *} p<0.05$ : treated vs. CTL. CTL: non-infected mice. TAM: tamoxifen. INF: infected.

In order to confirm whether tamoxifen treatment increases the proportions of myeloid cells, inflammatory monocytes, neutrophils and dendritic cells (Tip-DC) in the bone marrow and reduces them in the blood, we administered tamoxifen to mice before infection with A. baumannii, P. aeruginosa, and E. coli for $24 \mathrm{~h}$. Flow cytometric analysis demonstrated that in the bone marrow of mice infected with these pathogens, the percentage of myeloid cells 
and monocytes was higher in those treated with tamoxifen than in those that remained untreated. In contrast, the percentage of myeloid cells and monocytes in the blood of mice treated with tamoxifen was lower than in those untreated with tamoxifen (Figure 4A,B). A similar pattern was observed for the neutrophils and Tip-DC of mice infected with A. baumannii and P. aeruginosa (for neutrophils); however, in those infected with E. coli, tamoxifen did not significantly increase the percentage of neutrophils in bone marrow when compared with the untreated group (Figure 4C,D).

\section{A}

B

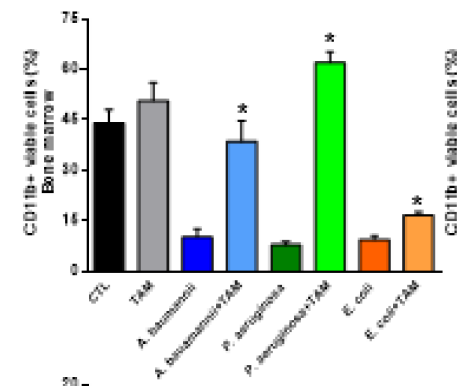

C
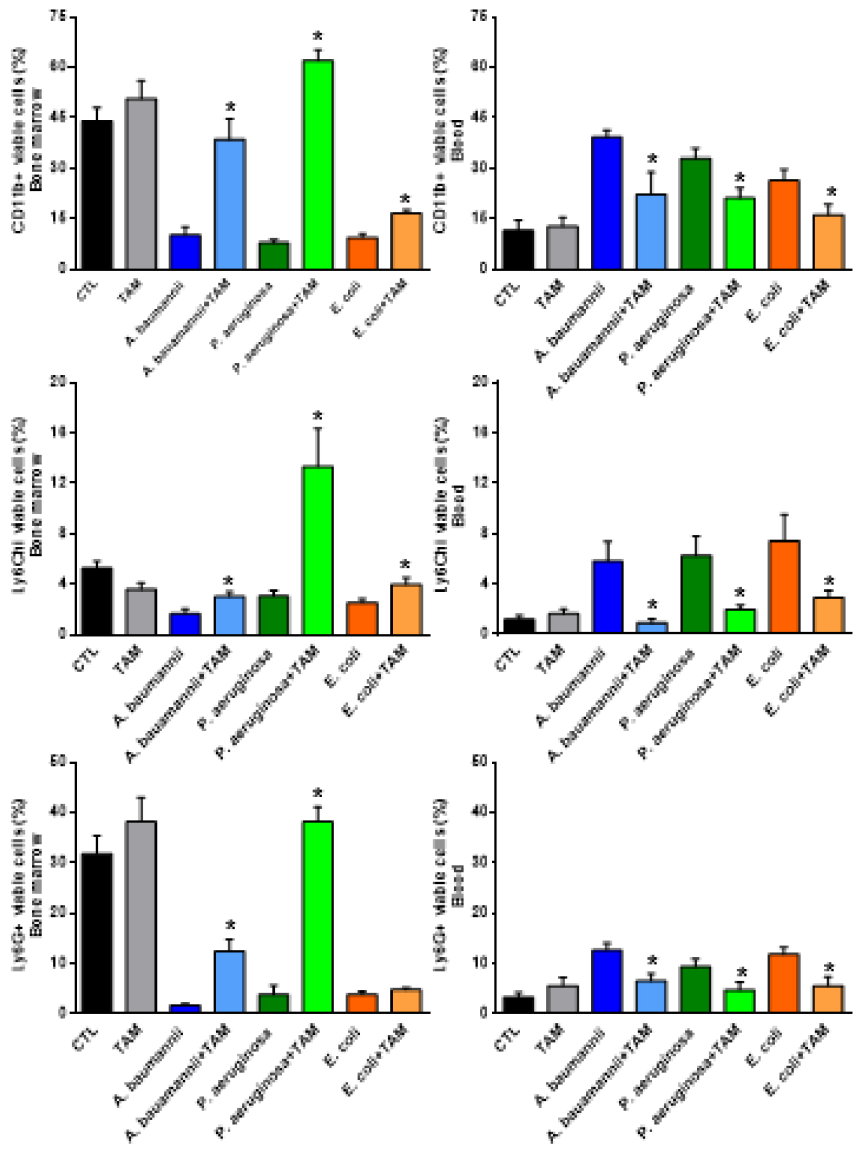

D
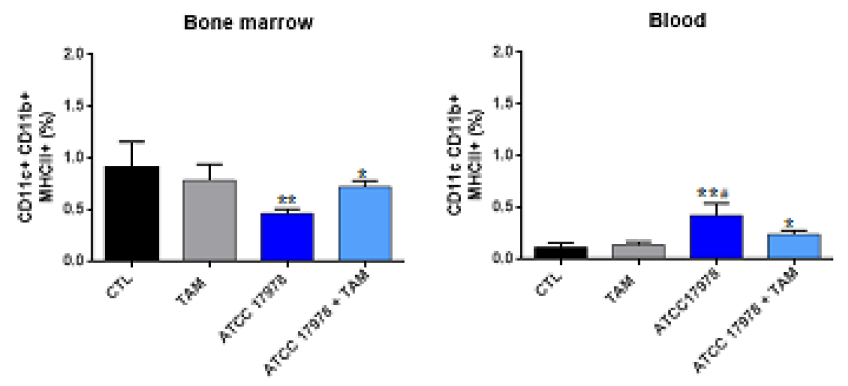

Figure 4. Tamoxifen impairs, after bacterial infection, the migration of immune cells from the bone marrow to the blood. Mice received firstly tamoxifen $(80 \mathrm{mg} / \mathrm{kg} / \mathrm{d}$, for three days), followed by infection with minimal lethal dose 100 of A. baumannii ATCC17978, P. aeruginosa PAO1, or E. coli ATCC25922 strains. Twenty-four hours post-infection, (A) myeloid cells, (B) inflammatory monocytes, (C) neutrophils and (D) Tip-DC were identified as CD11b+, CD11b+Ly6Chi , CD11b+Ly6G+, and $\mathrm{CD} 11 \mathrm{~b}+\mathrm{CD} 11 \mathrm{c}+\mathrm{MHII}+$ respectively, by flow cytometry in the bone marrow and blood of mice. Data are representative of five/six mice per group and are expressed as mean \pm SEM. ${ }^{*} p<0.05$ : treated vs. infected. ${ }^{* *} p<0.05$ : CTL vs. infected, ${ }^{\#} p<0.05$ : TAM vs. infected. CTL: non-infected mice, TAM: tamoxifen, \%: the percentage of myeloid cells, inflammatory monocytes, neutrophils and Tip-DC from total cells in bone marrow or blood. 
MCP-1 KO mice showed an impaired migration of inflammatory monocytes and neutrophils from the bone marrow to the blood after bacterial infection (Figure 2B,C). In order to determine whether tamoxifen is able to reduce this migration in mice deficient in MCP-1 secretions, we treated MCP-1 KO mice with tamoxifen and infected them with A. baumannii, P. aeruginosa, and E. coli. As shown in Figure 5A,B, tamoxifen-treated mice presented a reduction in the migration of inflammatory monocytes and neutrophils, despite the lack of MCP-1. Both populations were more present in the bone marrow, and concentrations in the blood were also reduced when compared with WT mice treated with tamoxifen and infected with these pathogens (except for inflammatory monocytes and neutrophils from mice infected by $P$. aeruginosa and E. coli, respectively), indicating that tamoxifen may regulate other chemokines and migration pathways involved in this phenomenon (Figures 5 and S2).

A

B
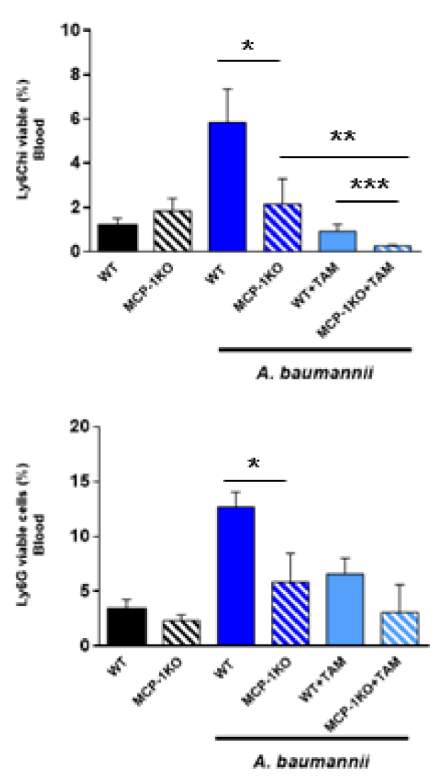
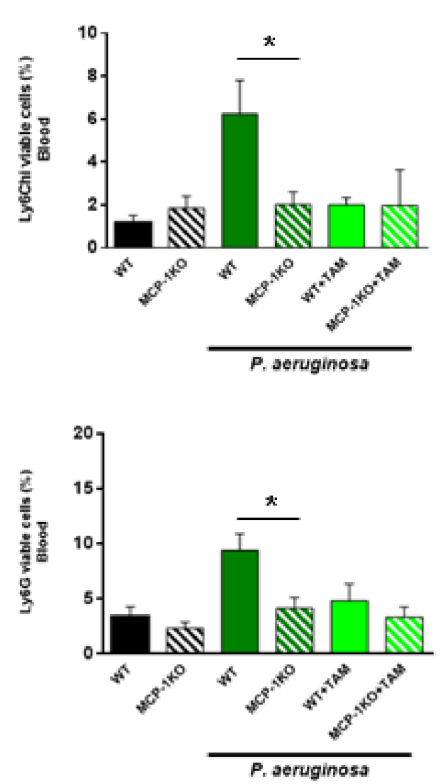
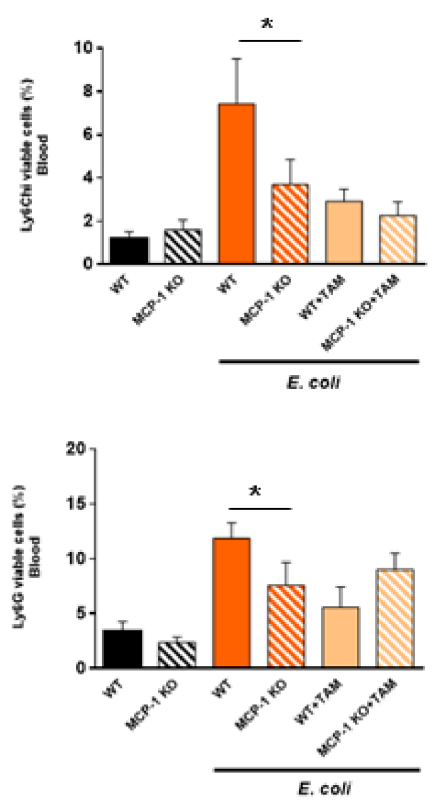

Figure 5. Tamoxifen impairs slightly, after bacterial infection in MCP-1-deficient mice, the migration of immune cells from the bone marrow to the blood through MCP-1 regulation. (A) WT and MCP-1 KO mice received firstly tamoxifen (80 mg/kg/d, for three days), followed by infection with a minimal lethal dose 100 of A. baumannii ATCC17978, P. aeruginosa PAO1, or E. coli ATCC25922 strains. Twenty-four hours post-infection, (A) inflammatory monocytes and (B) neutrophils were identified as $\mathrm{CD} 11 \mathrm{~b}+, \mathrm{CD} 11 \mathrm{~b}+\mathrm{Ly} 6 \mathrm{Chi}$, and $\mathrm{CD} 11 \mathrm{~b}+\mathrm{Ly} 6 \mathrm{G}+$, respectively, by flow cytometry in the bone marrow and blood of mice. Data are representative of six mice per group and are expressed as mean $\pm \mathrm{SEM}$. CTL: non-infected mice. ${ }^{*} p<0.05$ : infected WT vs. infected MCP-1 KO, ${ }^{* *} p<0.05$ : infected MCP-1 KO vs. infected MCP-1 KO + TAM, ${ }^{* *} p<0.05$ : infected WT + TAM vs. infected MCP-1 KO + TAM. CTL: non-infected mice, TAM: tamoxifen, \%: the percentage of inflammatory monocytes and neutrophils from total cells in blood.

\subsection{Tamoxifen Enhances Bacterial Killing by Macrophages and Neutrophils In Vitro}

Recent studies reported that treatment with tamoxifen enhances neutrophil activity by increasing the neutrophil extracellular traps (NETosis) and induces changes in macrophages by inhibiting the expression of CD36 and PPAR $\gamma$, thereby reducing atherosclerosis [26,27], but there are no data regarding the immune function of both cells treated with tamoxifen after a bacterial infection. To determine whether tamoxifen can increase the killing activity of macrophages and neutrophils, assays with the RAW 246.7 and HL-60 neutrophils cell lines, pretreated with tamoxifen and infected with $A$. baumannii, $P$. aeruginosa, and $E$. coli, were performed. We demonstrated that macrophage incubation with tamoxifen $(2.5 \mathrm{mg} / \mathrm{L})$ for 2 or $6 \mathrm{~h}$, followed by infection with A. baumannii for $2 \mathrm{~h}$, decreased the amount of bacteria within the macrophage by $10 \%$ and $30 \%$, respectively (Figure $6 \mathrm{~A}$ ), without affecting the amount of $A$. baumannii in the extracellular medium (Figure $6 \mathrm{~B}$ ). This 
suggests the increase of bacterial killing inside the macrophage after exposure to tamoxifen. Similar results were observed after treatment with tamoxifen and infection with $E$. coli, but not with P. aeruginosa (Figure 6A). Regarding neutrophil activity, incubation with $2.5 \mathrm{mg} / \mathrm{L}$ of tamoxifen for 2 or $6 \mathrm{~h}$, followed by infection with $A$. baumannii for $2 \mathrm{~h}$, increased bacterial killing by $5 \%$ and $25 \%$, respectively. Similar results were observed after treatment with tamoxifen and infection with E. coli, but not with P. aeruginosa (Figure 6A). Accordingly, tamoxifen treatment increases the killing activity of macrophages and neutrophils against A. baumannii and E. coli but not against P. aeruginosa.

A

\section{RAW 264.7}
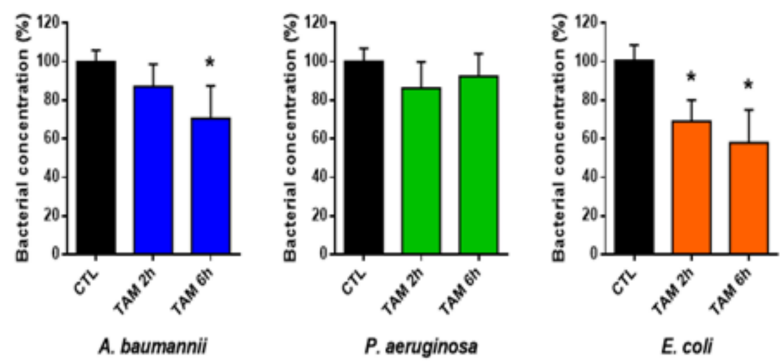

\section{HL-60 neutrophils}
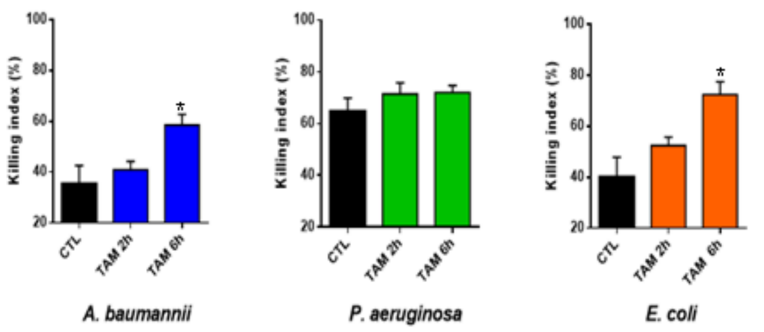

B

RAW 264.7
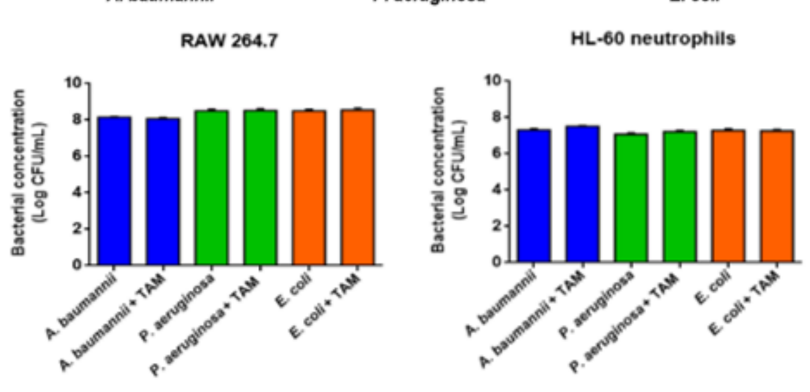

Figure 6. Tamoxifen induces the phagocytic activity of macrophages and neutrophils. RAW 264.7 cells and HL-60 neurophils were incubated with tamoxifen for 2 or $6 \mathrm{~h}$ and infected for $2 \mathrm{~h}$ with A. baumannii ATCC17978, P. aeruginosa PAO1, or E. coli ATCC25922 strains (MOI:100) (A) The adherence and invasion of these strains are expressed as the percentage of total control strain adhered or internalized to RAW 264.7 and the killing index of HL-60 neutrophil cells is expressed as the percentage. (B) The extracellular strains in the culture medium after $6 \mathrm{~h}$ of tamoxifen incubation are determined as Log colony-forming units (CFU)/mL. Data are representative of three independent experiments, and expressed as mean \pm SEM. ${ }^{*} p<0.05$ : treated vs. CTL. CTL: infected cells without tamoxifen treatment. TAM: tamoxifen.

\subsection{Tamoxifen Increases Mice Survival and Decreases the Bacterial Burden in a Murine Sepsis} Model of A. Baumannii, P. Aeruginosa, and E. Coli

Our results demonstrated that tamoxifen plays an important role in innate immune cells' trafficking after bacterial infection. Going further, we wanted to know whether tamoxifen could protect the mice against a lethal bacterial inoculum. We treated mice with tamoxifen $(80 \mathrm{mg} / \mathrm{kg} / \mathrm{d})$, administered intraperitoneally for three days before the infection with a minimal lethal dose 100 (MLD100) of $A$. baumannii, P. aeruginosa, and E. coli and we 
monitored the mice survival for three days. Pretreatment with tamoxifen increased the mice's survival after infection with A. baumannii, P. aeruginosa, and E. coli to $100 \%, 66.7 \%$, and $83.3 \%(p<0.01)$, respectively (Table 1$)$. Table 1 shows that treatment with tamoxifen decreased the spleen and lung bacterial concentrations of these pathogens by 6.64 and 7.16 $\log _{10}$ colony-forming units (CFU)/g $\left(p<0.015\right.$; for A. baumannii), by 3.58 and $5.1 \log _{10}$ CFU/g ( $p<0.015$; for P. aeruginosa), and by 3.7 and $4.16 \log 10$ CFU/g $(p<0.015$; for E. coli), compared with the control infected groups. Blood bacterial concentrations presented a decrease compared to control infected groups of 5.53, 5.45, and $4.31 \log _{10} \mathrm{CFU} / \mathrm{mL}(p<0.01)$ for A. baumannii, P. aeruginosa, and E. coli, respectively. Similar efficacy of tamoxifen was observed in a murine peritoneal sepsis model by susceptible and MDR clinical isolates of A. baumannii, P. aeruginosa, and E. coli. Treatment with tamoxifen increased the mice's survival to $66.7 \%, 83.3 \%$, and $50 \%(p<0.01)$ for non-MDR A. baumannii, P. aeruginosa, and E. coli, respectively, and $83.3 \%, 66.7 \%$, and $50 \%(p<0.01)$ for the MDR A. baumannii, $P$. aeruginosa, and E. coli harboring the $m c r-1$ gene (Figure 7). These findings indicate that tamoxifen treatment presents good therapeutic efficacy against reference and clinical isolates of A. baumannii, P. aeruginosa, and E. coli.

Table 1. Tamoxifen shows therapeutic efficacy in murine sepsis models by Gram-negative bacilli (GNB).

\begin{tabular}{|c|c|c|c|c|c|c|}
\hline \multirow{2}{*}{ Strain } & \multirow{2}{*}{ Treatment } & \multirow{2}{*}{$N$} & \multicolumn{3}{|c|}{ Bacterial Load $(\log$ CFU/g or mL \pm SEM) } & \multirow{2}{*}{$\begin{array}{l}\text { 3-Days Survival } \\
(\%)\end{array}$} \\
\hline & & & Spleen & Lung & Blood & \\
\hline A. baumannii & CTL & 6 & $9.51 \pm 0.17$ & $9.77 \pm 0.17$ & $6.14 \pm 0.94$ & 0 \\
\hline ATCC 17978 & TAM & 6 & $2.87 \pm 1.21^{\mathrm{a}}$ & $2.61 \pm 1.07^{\mathrm{a}}$ & $0.61 \pm 0.61^{\mathrm{a}}$ & $100^{\mathrm{a}}$ \\
\hline P. aeruginosa & CTL & 5 & $8.91 \pm 0.15$ & $9.24 \pm 0.17$ & $6.71 \pm 0.27$ & 0 \\
\hline PAO1 & TAM & 6 & $5.33 \pm 1.08^{b}$ & $4.14 \pm 1.50^{b}$ & $1.26 \pm 1.26^{b}$ & $66.7^{\mathrm{b}}$ \\
\hline E. coli & CTL & 6 & $8.71 \pm 0.05$ & $8.88 \pm 0.16$ & $8.18 \pm 0.37$ & 0 \\
\hline ATCC 25922 & TAM & 6 & $5.01 \pm 1.20^{\mathrm{c}}$ & $4.72 \pm 1.08^{c}$ & $3.87 \pm 0.99^{c}$ & $83.3^{c}$ \\
\hline
\end{tabular}

CTL: control receiving corn oil as vehicle control; TAM: tamoxifen. ${ }^{\mathrm{a}, \mathrm{b}, \mathrm{c}}: p<0.05$ : treated vs. untreated.
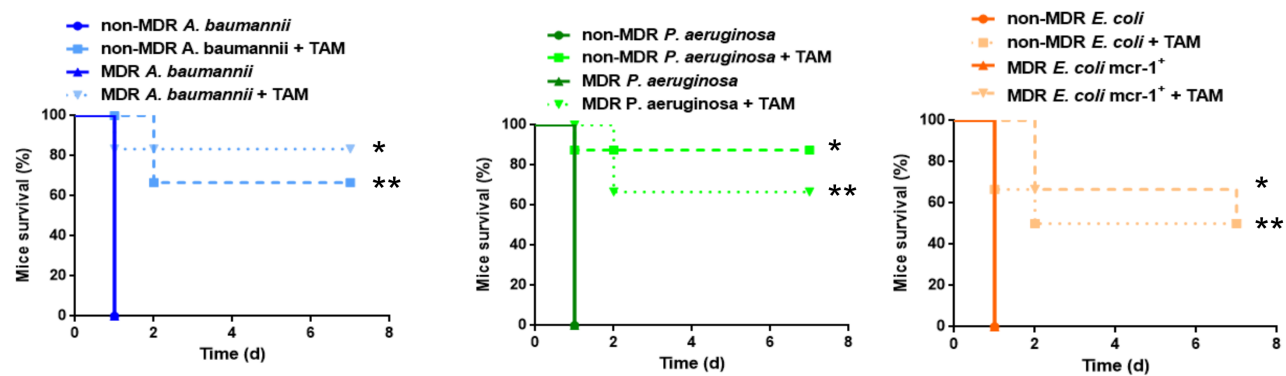

Figure 7. Tamoxifen increases the survival of mice infected with non-MDR or MDR GNB. Mice survival was monitored during 7 days for 6 mice infected with MLD100 of non-MDR and MDR A. baumannii (Ab9 and Ab186), P. aeruginosa (Pa39 and Pa238) or E. coli (C1-7-LE and EcMCR+) strains treated or not with 3 ip. doses of tamoxifen $\left(80 \mathrm{mg} / \mathrm{kg} / \mathrm{d}\right.$, for 3 days). ${ }^{*} p<0.05$ : treated vs. untreated, ** $p<0.05$ : treated vs. untreated, TAM: tamoxifen, MDR: multidrug-resistant.

2.5. Direct Treatment with Tamoxifen Increases Mice Survival and Decreases the Bacterial Burden in a Murine Sepsis Model of A. Baumannii

In order to demonstrate the efficacy of tamoxifen in mice already infected with A. baumannii we have used the recommend dose of $250 \mathrm{mg} / \mathrm{kg}$ by Corriden et al. 2015 [26] administered in 6 infected mice $2 \mathrm{~h}$ post-bacterial inoculation. We found that tamoxifen treatment reduced the bacterial loads in spleen, lungs and blood to $5.37 \pm 1.43 \log \mathrm{CFU} / \mathrm{g}$ $(p=0.02), 6.72 \pm 0.62 \log \mathrm{CFU} / \mathrm{g}(p=0.0007)$ and $3.74 \pm 1.29 \log \mathrm{CFU} / \mathrm{mL}(p=0.33)$, respectively, and increased mice survival to $50 \%(p=0.01)$. 


\section{Discussion}

The present study provides new data highlighting the antibacterial effect of tamoxifen. Here, we provide the first evidence of an essential role played by tamoxifen in the regulation of immune cells' traffic after bacterial infection, in order to reduce the hyperinflammation caused by sepsis.

This study, as well as previous works [13,14], showed that the regulation of inflammatory monocytes' and neutrophils' migration is important in the host defense against bacterial infections. This is consistent with the immune system modulation that improves the bacterial infection clearance [9]. Exploiting immunomodulatory drugs approved by the regulatory agencies for clinical indications different to bacterial infection therapy has several advantages [28], including the fact that their pharmacological characteristics (toxicity and pharmacokinetics) in preclinical and clinical trials are available. Therefore, the time and economic costs of the evaluation of these drugs in other therapeutic applications, such as the treatment of bacterial infections, will be reduced [29].

Here, we showed that tamoxifen reduces the release of MCP- 1 and IL-18, and the phosphorylation of ERK. We suggest that the reduction of IL-18 secretion by tamoxifen may drive the reduction of MCP-1 release through a reduction of ERK phosphorylation, which would contribute to efficient reduction of the migration of inflammatory monocytes and neutrophils from the bone marrow to the blood. It is well known that, during sepsis, bacterial infection releases high levels of harmful substances, resulting in the activation of systemic immune response and the development of hyperinflammation [30,31]. Thus, the decrease of certain immune cells' migration to the bloodstream and their activation may reduce the hyperinflammation state and the secondary deleterious effects observed in sepsis.

Recruitment of immune cells from the bone marrow to the blood during systemic infection with GNB is probably mediated by multiple pathways dependent on or independent of MCP-1, such as MyD88 and MIP-2 [32-34]. MyD88 has been reported to induce MCP-1 release of macrophages after their infection with Listeria monocytogenes [32]. In contrast, to our knowledge, MIP-2 is not involved in the release of MCP-1 by eukaryotic ells. The presence of pathways independent of MCP- 1 has been confirmed in a study of MCP-1 KO mice infected with A. baumannii, P. aeruginosa, and E. coli, in which inflammatory monocytes and neutrophils migrate at lower levels from the bone marrow to the bloodstream. Previous independent work reported that the deletion of MCP-1 in mice did not completely abolish the recruitment of monocytes during infection with L. monocytogenes; this recruitment was diminished by $40-50 \%$ [35], suggesting the involvement of MCP-3, another monocyte chemoattractant protein, after binding to the CCR2 receptor in the systemic bacterial infection [36]. Regarding neutrophils, although it is widely accepted that MIP-2 stimulates their migration from the bone marrow [37,38], we demonstrated for the first time that in MCP-1 KO mice the migration of neutrophils from the bone marrow to the bloodstream after GNB infection was diminished, suggesting the involvement of MCP-1 in this process. This result is consistent with the previous observation that MCP-1 regulates the recruitment of neutrophils to the lungs after E. coli infection [34]. Based on these data, MCP-1 plays an important role in the migration of inflammatory monocytes and neutrophils from the bone marrow to the bloodstream. However, this migration in MCP-1 $\mathrm{KO}$ mice infected with GNB and treated with tamoxifen is reduced but not abolished. A possible explanation could be the involvement of other MCP-1-independent pathways regulated by tamoxifen. In this context, further studies are required to decipher the role of these MCP-1-independent pathways in this process.

A consequence of the reduction in monocyte proportions in the blood after treatment with tamoxifen would be the reduction of macrophages and dendritic cells in the blood and tissues. Although the number of macrophages and neutrophils recruited to the sites of infection in mice treated with tamoxifen was lower, our in vitro assays suggested that their killing activity against $A$. baumannii and $E$. coli was enhanced by tamoxifen. The inflammatory monocytes are the precursors of a subset of dendritic cells (Tip-DC) that produce tumor 
necrosis factor- $\alpha$ (TNF- $\alpha$ ) and inducible oxide synthase (iNOS), contributing to the innate defense against L. monocytogenes infection $[39,40]$. In contrast, another study reported that the reduction of proinflammatory monocytes and Tip-DC during Trypanosoma brucei infection diminished their pathogenicity [41]. These contradictory results in terms of the effect of monocytes and Tip-DC recruitment on host survival could be explained by the difference in cellular location of each pathogen: L. monocytogenes is intracellular, whereas T. brucei remains in the plasma [14]. Moreover, it is reported that tamoxifen inhibits the maturation of TipDC in vitro, in the presence of $17 \beta$-estradiol, which does not respond sufficiently to bacterial LPS [42]. We suggest that the reduction in the dendritic cells' proportions, along with their stunted maturation after tamoxifen treatment, produced a reduction in TNF- $\alpha$ and iNOS production, minimizing their deleterious effects in sepsis situations. Of note, in our study, we found that treatment with tamoxifen reduced the proportions of Tip-DC in blood and the release of proinflammatory cytokines such as TNF- $\alpha$ and IL-6 (Figures 4D and S3). Accordingly, although we previously pointed out that $A$. baumannii could support intracellular life $[43,44]$, the bacterial species used in our study are viewed as extracellular pathogens and are present in the blood. Consequently, it is possible that in our model, the reduction of monocyte and Tip-DC concentration by tamoxifen treatment, and the reduction of proinflammatory cytokines' release, may play an important role in the therapeutic efficacy of tamoxifen.

In this study, differences were observed when P. aeruginosa was the infecting pathogen of macrophages versus E. coli and A. baumannii (Figure 6). We suggest that the differences observed when $P$. aeruginosa is the infecting agent versus $E$. coli and $A$. baumannii is due to the virulence factors present in P. aeruginosa. Previous reports showed that P. aeruginosa was less ingested by macrophages than E. coli [45]. P. aeruginosa enters and survives inside primary human and murine macrophages. This entrance depends on the expression of OprF, the most abundant bacterial outer membrane protein (OMP)/porin, the type III secretion system, and the exoS [46,47]. In addition, other authors have demonstrated that murine macrophages are more sensitive to the type III secretion system of $P$. aeruginosa than that of E. coli [48]. Regarding the comparison between P. aeruginosa and A. baumannii, a similar pattern has been observed with E. coli. P. aeruginosa persists more than $A$. baumannii inside normoxic and hypoxic murine macrophages [49]. Additional studies are needed to understand how tamoxifen increases the macrophages and neutrophils killing of $A$. baumannii and E. coli, and which mechanism used by P. aeruginosa to avoid this killing.

Tamoxifen dosage used in this study was $1.6 \mathrm{mg} / \mathrm{d}$ for three days. Only one study has reported in vivo the beneficial effect of tamoxifen against infection by Gram-positive bacterium Staphylococcus aureus [26]. They used a non-toxic dose of tamoxifen at $250 \mathrm{mg} / \mathrm{kg}$ ( $5 \mathrm{mg} / \mathrm{d}$ for 1 day) to treat mice infected by S. aureus [26]. We have analysed the toxicity effect of tamoxifen in mice at lower and higher doses of tamoxifen: $80 \mathrm{mg} / \mathrm{kg}(1.6 \mathrm{mg} / \mathrm{d}$, the dosage used in our preventive experiments), $160 \mathrm{mg} / \mathrm{kg}(3.2 \mathrm{mg} / \mathrm{d})$ and $320 \mathrm{mg} / \mathrm{kg}$ $(6.4 \mathrm{mg} / \mathrm{d})$, for three days by monitoring the mice survival for 7 days. We found that tamoxifen at 1.6 and $3.2 \mathrm{mg} / \mathrm{d}$ did not affect the mice survival being 100\%, and tamoxifen at $6.4 \mathrm{mg} / \mathrm{d}$ reduced the mice survival to $83.33 \%$. The cumulative doses of tamoxifen at $1.6 \mathrm{mg} / \mathrm{d}$ for three days of treatment correspond to $4.8 \mathrm{mg} / \mathrm{d}$ which is below to $5 \mathrm{mg} / \mathrm{d}$ in the study performed by Corriden et al. [26], and below the cumulative doses of $9.6 \mathrm{mg} / \mathrm{d}$ which did not affect the mice survival in our toxicity studies.

Data on the therapeutic efficacy of high tamoxifen dosages against GNB infections are not available. The next issue that must be addressed is to determine (i) the therapeutic efficacy of high tamoxifen dosages against A. baumannii, P. aeruginosa and E. coli infections, and (ii) whether tamoxifen given as direct treatment after bacterial infections will have an impact on bacterial burdens and mice survival against $P$. aeruginosa and E. coli, as a first step before evaluation in clinical studies. In addition, we need to determine the pharmacokinetic parameters of tamoxifen at $80 / \mathrm{mg} / \mathrm{kg}$ ip. for 3 days in order to compare with those achieved in humans receiving tamoxifen at $40 \mathrm{mg} / \mathrm{d}$ po. for breast cancer treatment. 


\section{Materials and Methods}

\subsection{Reagents}

Tamoxifen, porcine mucin, and protease inhibitors were obtained from Sigma, Spain.

\subsection{Bacterial Strains}

Reference A. baumannii ATCC 17978 [50], P. aeruginosa PAO1 [51] and E. coli ATCC 25922 [52] strains were used. We also used two clinical susceptible (Ab9) and multidrugresistant (MDR) (Ab186) A. baumannii from the REIPI-GEIH 2010 collection [10], two clinical susceptible (Pa39) and MDR (Pa238) P. aeruginosa from the REIPI-GEIH 2008 collection [53], and two clinical susceptible (C1-7-LE) and MDR (EcMCR+, carrying mcr-1 gene) E. coli $[54,55]$.

\subsection{Animals}

Immunocompetent C57BL/ 6 female mice (16-18 g) were obtained from the University of Seville. MCP-1 KO mice were generated with a C57BL/ 6 background and obtained from Jackson Laboratory, USA. All mice were pathogen-free, were assessed for genetic authenticity, and were housed in regulation cages with food and water available ad libitum. This study was carried out in strict accordance with the protocol approved by the Committee on the Ethics of Animal Experiments of the University Hospital of Virgen del Rocío, Seville (0704-N-18). All surgery was performed under sodium thiopental anesthesia and all efforts were made to minimize suffering.

\subsection{A. Baumannii, P. Aeruginosa, and E. Coli Peritoneal Sepsis Models}

Murine peritoneal sepsis models with A. baumannii, P. aeruginosa, or E. coli strains were established by ip. inoculation of the bacteria in immunocompetent mice [7]. Briefly, six mice from each group were inoculated with the minimal bacterial lethal dose 100 (MLD100) of the bacterial suspensions, mixed in a 1:1 ratio with a saline solution containing $10 \%(w / v)$ porcine mucin. The MLD100 of ATCC 17978, Ab9, Ab186, PAO1, Pa39, Pa238, ATCC 25922, C1-7-LE, and EcMCR-1+ were 3.2, 5.9, 5.0, 4.9, 3.85, 6.7, 4.7, 2.91, and $6 \log _{10} \mathrm{CFU} / \mathrm{mL}$, respectively. Mortality was recorded over three or seven days. After the death or sacrifice of the mice at the end of the experimental period, aseptic thoracotomies were performed, and blood samples were obtained by cardiac puncture. The spleen and lungs were aseptically removed and homogenized (Stomacher 80 Biomaster; Seward, London, England) in $2 \mathrm{~mL}$ of sterile $\mathrm{NaCl} 0.9 \%$ solution. Ten-fold dilutions of the homogenized spleen, lungs and blood were plated onto sheep blood agar (Becton Dickinson Microbiology Systems, USA) for quantitative cultures. If no growth was observed after plating the whole residue of the homogenized tissue and blood, a logarithm value corresponding to the limit of detection of the method (1 CFU) was assigned.

\subsection{Therapeutic Effect of Tamoxifen in Immunocompetent Murine Models of Peritoneal Sepsis}

The immunocompetent murine peritoneal sepsis models by A. baumannii (ATCC 17978, Ab9 and Ab186), P. aeruginosa (PAO1, Pa39 and Pa238), or E. coli (ATCC 25922, C1-7-LE and EcMCR-1+) strains were established by ip. inoculation of the bacteria in immunocompetent mice. Briefly, six animals from each group were infected ip. with $0.5 \mathrm{~mL}$ of the MLD100 of each strain mixed 1:1 with $10 \%$ porcine mucin. Tamoxifen therapy was administered for three days at one safe dose of $80 \mathrm{mg} / \mathrm{kg} / \mathrm{d}$, using corn oil as a vehicle [26], before bacterial inoculation. Mice were randomly assigned to the following groups: (1) controls (receiving corn oil as vehicle control), and (2) Tamoxifen administered at $80 \mathrm{mg} / \mathrm{kg} / \mathrm{d}$ ip. for three days before bacterial inoculation with each strain.

In addition, we have treated other six mice with tamoxifen at one dose of $250 \mathrm{mg} / \mathrm{kg}$ $2 \mathrm{~h}$ post-inoculation with MLD100 of A. baumannii ATCC 17978 strains. Mortality and bacterial loads in tissues and blood were determined, as described in a previous section. 


\subsection{Flow Cytometry}

Blood and bone marrow cells and spleen samples were prepared from control and infected mice with DML100 of ATCC 17978, PAO1, and ATCC 25922 strains and pretreated or not with tamoxifen, as described before [8,56]. Briefly, blood samples were harvested from mouse periorbital plexuses and resuspended in Ethylenediaminetetraacetic acid (EDTA). Bone marrow cells were collected by flushing mouse femurs with ice-cold phosphate-buffered saline (PBS), and red blood cells were depleted by lysis in a lysis buffer containing $0.15 \mathrm{M} \mathrm{NH}_{4} \mathrm{Cl}, 0.01 \mathrm{M} \mathrm{KHCO}_{3}$, and $0.01 \mathrm{M}$ of disodium-EDTA. Spleen samples were harvested, homogenized, and filtered through a 20- $\mu \mathrm{m}$ mesh prior to red blood cells' depletion by a lysis buffer. Bone marrow and spleen samples were lysed by a lysis buffer for $10 \mathrm{~min}$ at $4{ }^{\circ} \mathrm{C}$, whereas blood samples were lysed for $10 \mathrm{~min}$ at room temperature. Cells (1-2 $\times 10^{6}$ cells per sample) were resuspended in PBS with $2 \%$ fetal bovine serum (FBS) and then incubated with the appropriate dilution of antibody conjugates. Samples were analyzed with LSRFortessa Flow Cytometer (BD Biosciences, Franklin Lakes, NJ, USA) and the data obtained were analyzed with DIVA software (BD Biosciences). The staining protocols included a combination of the following antibodies: anti-CD11b (clone M1/70, Allophycocyanin (APC)), anti-Ly6C (clone, AL-21, fluorescein isothiocyanate (FITC)), anti-Ly6G (clone 1A8, PE), anti-CD4 (Clone GK1.5, PE), anti-CD8 (Clone 53-6.7, PE-Cy7), anti-CD11c (clone N418, BV421) and anti-I-A/I-E (clone M5/114.15.2) (BD Biosciences, Spain), and anti-CD19 (Clone 6D5, Brilliant Violet 421) (BioLegend, Spain) diluted at 1:300 in PBS with $2 \%$ fetal bovine serum.

\subsection{Cytokine Assays}

Blood samples were collected from the periorbital plexuses of mice infected with DML100 of ATCC 17978, PAO1, and ATCC 25922 strains and pretreated or not with tamoxifen, as previously described [11]. Serum levels of murine MCP-1, IL-6, IL-18, and TNF- $\alpha$ were collected 6 and $24 \mathrm{~h}$ post-bacterial infection, without or with tamoxifen treatment. MCP-1, IL-6, IL-18, and TNF- $\alpha$ levels were determined by ELISA kit (ThermoFisher, for MCP-1) and (Affymetrix eBioscience, for IL-6, IL-18, and TNF- $\alpha$ ) in accordance with the manufacturer's instructions. Furthermore, the extracellular medium of RAW 264.7 macrophage cells infected with $8 \log _{10}$ CFU / mL of ATCC 17978, PAO1, and ATCC 25922, and previously pre-incubated or not with $2.5 \mathrm{mg} / \mathrm{L}$ tamoxifen for $24 \mathrm{~h}$, was collected to determine the MCP-1 levels.

\subsection{Cell Culture and Infection}

Macrophage cell line RAW 264.7 was obtained from the American Type Culture Collection (LGC, UK) and grown in Dulbecco's modified Eagle medium (DMEM, Invitrogen, Spain) supplemented with $10 \%$ heat-inactivated fetal bovine serum, vancomycin $(50 \mathrm{mg} / \mathrm{L})$, gentamicin $(20 \mathrm{mg} / \mathrm{L})$, amphotericin B $(0.25 \mathrm{mg} / \mathrm{L})$ (Invitrogen), and 1\% HEPES (Invitrogen) in a humidified incubator, $5 \% \mathrm{CO}_{2}$ at $37{ }^{\circ} \mathrm{C}$, as described previously [49]. RAW 264.7 cells were routinely passaged every $3-4$ days. The cells were seeded for $24 \mathrm{~h}$ in 24 -well plates before bacterial infection for Western blot and adhesion assays.

Human promyelocytic leukemia HL-60 cells (ATCC CCL-240) were grown in RPMI 1640 medium (GE Healthcare Life Sciences, Spain) supplemented with $10 \%$ heat-inactivated fetal bovine serum, $2 \mathrm{mM}$ L-glutamine (Sigma, Spain), $25 \mathrm{mM}$ HEPES, and a penicillin/ streptomycin solution in a humidified incubator, $5 \% \mathrm{CO}_{2}$ at $37^{\circ} \mathrm{C}$. HL-60 cells' culture and differentiation were performed as previously described with minor changes [57]. HL-60 cells were incubated with 1.3\% DMSO (Sigma, Spain) for seven days and their differentiation into neutrophils (referred to as HL-60 neutrophils) was monitored by flow cytometry analysis, using anti-CD11b (clone ICRF44, APC) (BioLegend) and DAPI as viability markers. 


\subsection{Western Blot Immunoblotting}

Proteins of infected RAW 264.7 macrophage cells with $8 \log _{10}$ CFU / mL of ATCC 17978, PAO1 and ATCC 25922, preincubated or not with $2.5 \mathrm{mg} / \mathrm{L}$ tamoxifen, were collected, homogenized in RIPA buffer supplemented with $1 \mathrm{mM}$ phenylmethylsulfonyl fluoride (PMSF) and a 10\% cocktail of protease inhibitors, and centrifuged at $13,000 \times g$ for $20 \mathrm{~min}$ at $4{ }^{\circ} \mathrm{C}$. The supernatant was removed and the amount of proteins was determined using the BCA assay (Promega, Spain). The samples were stored at $-80^{\circ} \mathrm{C}$ until later use. Six micrograms of proteins of each sample were mixed with an equal volume of $2 \times$ Laemmli buffer, denatured by heating the mixture for $5 \mathrm{~min}$ at $95^{\circ} \mathrm{C}$, and then resolved by $4-15 \%$ sodium dodecyl sulfate polyacrylamide gel electrophoresi (SDS-PAGE). The separated proteins were transferred using polyvinylidene fluoride (PVDF) membranes (Amersham Bioscience, Spain), and the membranes were blocked for $2 \mathrm{~h}$ with PBS and $0.1 \%(v / v)$ Tween 20 (PBST buffer) containing 5\% $(w / v)$ milk. The PVDF membranes were then incubated overnight at $4{ }^{\circ} \mathrm{C}$ with primary antibody: rabbit anti-mouse p44/42 MAPK (Erk1/2) (1:1000 dilution), Phospho-p44/42 MAPK (Erk1/2) (1:1000 dilution) and $\beta$-actin (1:1000 dilution) (Cell Signaling Technology, Spain) diluted in a PBST buffer containing $5 \%$ milk. After washing with PBST buffer, the membranes were incubated for $1 \mathrm{~h}$ at room temperature with a horseradish peroxidase-conjugated donkey anti-rabbit IgG as secondary antibody (GE Healthcare, Spain) (dilution 1:2000) diluted in a PBST buffer containing $5 \%$ milk. Subsequently, immunoreactive proteins were visualized using the enhanced chemiluminescence protocol (Super ECL, Thermo Scientific, USA).

\subsection{Macrophages Adhesion Assay}

RAW 264.7 cells were pretreated with $2.5 \mathrm{mg} / \mathrm{L}$ tamoxifen for 2,6 , or $24 \mathrm{~h}$; and infected with ATCC 17978, PAO1, and ATCC 25922 strains (MOI 1:100) for $2 \mathrm{~h}$ with 5\% $\mathrm{CO}_{2}$ at $37^{\circ} \mathrm{C}$. Subsequently, infected RAW 264.7 macrophage cells were washed five times with prewarmed PBS and lysed with $0.5 \%$ Triton X-100. Diluted lysates were plated onto sheep's blood agar and incubated at $37^{\circ} \mathrm{C}$ for $24 \mathrm{~h}$ for the enumeration of developed colonies and then the determination of the number of bacteria that attached to and invaded RAW 264.7 cells. Alternatively, we determined the concentration of the extracellular medium bacteria after $6 \mathrm{~h}$ of tamoxifen incubation by plating diluted extracellular medium onto sheep's blood agar.

\subsection{Neutrophil Killing Assay}

HL-60 neutrophils were pretreated with $2.5 \mathrm{mg} / \mathrm{L}$ for 2 or $6 \mathrm{~h}$; and infected with ATCC 17978, PAO1, and ATCC 25922 strains (MOI 1:100) for $2 \mathrm{~h}$ with $5 \% \mathrm{CO}_{2}$ at $37^{\circ} \mathrm{C}$. Subsequently, HL-60 neutrophils were washed five times with prewarmed PBS by centrifugation and lysed with $0.5 \%$ Triton X-100. Diluted lysates were plated onto sheep's blood agar and incubated at $37^{\circ} \mathrm{C}$ for $24 \mathrm{~h}$ for the enumeration of developed colonies and then the determination of the number of bacteria. The neutrophil killing index was calculated according to the formula [(CFU in the absence of neutrophils- $\mathrm{CFU}$ in the presence of neutrophils)/CFU in the absence of neutrophils] $\times 100$ [57].

\subsection{Statistical Analysis}

Group data are presented as means \pm standard errors of the means (SEM). For in vitro studies, Student's $t$-test was used to determine the differences between means. Differences in bacterial spleen, lung, and blood concentrations (mean $\pm \mathrm{SEM} \log _{10} \mathrm{CFU}$ per $\mathrm{g}$ or $\mathrm{mL}$ ) were assessed by analysis of variance (ANOVA) and post hoc Dunnett's and Tukey's tests. Differences in mortality (\%) between groups were compared by use of the $\chi^{2}$ test. $p$ values of $<0.05$ were considered significant. The SPSS (version 21.0; SPSS Inc.) statistical package was used. 


\section{Conclusions}

Together, these data suggest that treatment with tamoxifen may be useful as prophylaxis in hospitalized patients with a risk of infection with Gram-negative bacilli.

Supplementary Materials: The following are available online at https://www.mdpi.com/article/10 .3390 / ph14060507/s1, Figure S1: Populations of B lymphocytes and T lymphocytes CD4+ and CD8+ in bone marrow, blood and spleen during bacterial infection, Figure S2: Role of MCP-1 in the bone marrow immune cells migration to blood during bacterial infection. Figure S3: Tamoxifen effect on cytokines release after bacterial infection. Table S1: Populations of myeloid origin cells, monocytes and neutrophils in the spleen of mice infected with MLD100 of A. baumannii ATCC17978, P. aeruginosa PAO1 or E. coli ATCC25922 strains after $24 \mathrm{~h}$.

Author Contributions: M.E.-J.M., J.P. and Y.S. conceptualized the study and designed the experiments, analyzed the results and wrote the manuscript. A.M.-C., R.d.T. and R.A.-A. performed the experiments and analyzed the results. J.P. reviewed the manuscript. All authors have read and agreed to the published. All authors have read and agreed to the published version of the manuscript.

Funding: This study was supported by the Instituto de Salud Carlos III, Proyectos de Investigación en Salud (grants CP15/00132, PI16/01378 and PI19/01453) and by Plan Nacional de I+D+i 2013-2016 and Instituto de Salud Carlos III, Subdirección General de Redes y Centros de Investigación Cooperativa, Ministerio de Ciencia, Innovación y Universidades, Spanish Network for Research in Infectious Diseases (REIPI RD16/0016/0009)—co-financed by European Development Regional Fund “A way to achieve Europe", Operative program Intelligent Growth 2014-2020. Younes Smani is supported by the Subprograma Miguel Servet Tipo I from the Ministerio de Economía y Competitividad of Spain (CP15/00132).

Institutional Review Board Statement: This study was carried out in strict accordance with the recommendations in the Guide for the Care and Use of Laboratory Animals [National Research Council. Guide for the Care and Use of Laboratory Animals, 8th ed.; National Academies Press: Washington, DC, USA, 2011.]. The protocol was approved by the Committee on the Ethics of Animal Experiments of the University Hospital of Virgen del Rocío of Seville, Spain (approval 0704-N-18).

Informed Consent Statement: Not applicable.

Data Availability Statement: The data presented in this study are available in the article and supplementary material.

Acknowledgments: We thank José Manuel Rodríguez Martinez for the kind gift of the EcMCR+ strain.

Conflicts of Interest: The authors declare no conflict of interest.

\section{References}

1. Valero, C.; Garcia Palomo, J.D.; Mattoras, P.; Fernández-Mazarrasa, C.; Gonzales-Fernández, C.; Farinas, M.C. Acinetobacter bacteraemia in a teaching hospital, 1989-1998. Eur. J. Int. Med. 2001, 12, 425-429. [CrossRef]

2. Annane, D.; Bellissant, E.; Cavaillon, J.M. Septic shock. Lancet 2005, 365, 63-78. [CrossRef]

3. Martin, G.S.; Mannino, D.M.; Eaton, S.; Moss, M. The epidemiology of sepsis in the United States from 1979 through 2000. N. Engl. J. Med. 2003, 348, 1546-1554. [CrossRef] [PubMed]

4. Walkey, A.J.; Lagu, T.; Lindenauer, P.K. Trends in sepsis and infection sources in the US. A population-based study. Ann. Am. Thorac. Soc. 2015, 12, 216-220. [CrossRef]

5. Garnacho-Montero, J.; Garcia-Garmendia, J.L.; Barrero-Almodovar, A.; Jiménez-Jiménez, F.J.; Pérez-Paredes, C.; Ortiz-Leyba, C. Impact of adequate empirical antibiotic therapy on the outcome of patients admitted to the intensive care unit with sepsis. Crit. Care Med. 2003, 31, 2742-2751. [CrossRef]

6. Rasko, D.V.; Sperandio, V. Anti-virulence strategies to combat bacteria-mediated disease. Nat. Rev. Drug Discov. 2010, 9, 117-128. [CrossRef]

7. Vila-Farrés, X.; Parra-Millán, R.; Sánchez-Encinales, V.; Varese, M.; Ayerbe-Algaba, R.; Bayó, N.; Guardiola, S.; Pachón-Ibáñez, M.E.; Kotev, M.; García, J.; et al. Combating virulence of Gram-negative bacilli by OmpA inhibition. Sci. Rep. 2017, 7, 14683. [CrossRef] [PubMed]

8. Smani, Y.; Domínguez-Herrera, J.; Ibáñez-Martínez, J.; Pachón, J. Therapeutic efficacy of lysophosphatidylcholine in severe infections caused by Acinetobacter baumannii. Antimicrob. Agents Chemother. 2015, 59, 3920-3924. [CrossRef] [PubMed]

9. Wright, G.D. Antibiotic adjuvants: rescuing antibiotics from resistance. Trends Microbiol. 2016, 24, 862-871. [CrossRef] [PubMed] 
10. Parra Millán, R.; Jiménez Mejías, M.E.; Sánchez Encinales, V.; Ayerbe Algaba, R.; Gutiérrez Valencia, A.; Pachón Ibáñez, M.E.; Díaz, C.; Pérez Del Palacio, J.; López Cortés, L.F.; Pachón, J.; et al. Efficacy of lysophosphatidylcholine in combination with antimicrobial agents against Acinetobacter baumannii in experimental murine peritoneal sepsis and pneumonia models. Antimicrob. Agents Chemother. 2016, 60, 4464-4470. [CrossRef] [PubMed]

11. Miyazaki, H.; Midorikawa, N.; Fujimoto, S.; Miyoshi, N.; Yoshida, H.; Matsumoto, T. Antimicrobial effects of lysophosphatidylcholine on methicillin-resistant Staphylococcus aureus. Ther. Adv. Infect. Dis. 2017, 4, 89-94. [PubMed]

12. Zhao, L.; Kuo Lee, R.; Harris, G.; Tram, K.; Yan, H.; Chen, W. c-di-GMP protects against intranasal Acinetobacter baumannii infection in mice by chemokine induction and enhanced neutrophil recruitment. Int. Immunopharmacol. 2011, 11, 1378-1383. [CrossRef] [PubMed]

13. Nathan, C. Neutrophils and immunity: challenges and opportunities. Nat. Rev. Immunol. 2006, 6, 173-182. [CrossRef] [PubMed]

14. Shi, C.; Pamer, E.G. Monocyte recruitment during infection and inflammation. Nat. Rev. Immunol. 2011, 11, 762-774. [CrossRef] [PubMed]

15. Shi, C.; Jia, T.; Mendez-Ferrer, S.; Hohl, T.M.; Serbina, N.V.; Lipuma, L.; Leiner, I.; Li, M.O.; Frenette, P.S.; Pamer, E.G. Bone marrow mesenchymal stem and progenitor cells induce monocyte emigration in response to circulating toll-like receptor ligands. Immunity 2011, 34, 590-601. [CrossRef]

16. Yoo, J.K.; Kwon, H.; Khil, L.Y.; Zhang, L.; Jun, H.S.; Yoon, J.W. IL-18 induces monocyte chemotactic protein-1 production in macrophages through the phosphatidylinositol 3-kinase/Akt and MEK/ERK1/2 pathways. J. Immunol. 2005, 175, 8280-8286. [CrossRef] [PubMed]

17. Bossink, A.W.; Paemen, L.; Jansen, P.M.; Hack, C.E.; Thijs, L.G.; Van Damme, J. Plasma levels of the chemokines monocyte chemotactic proteins-1 and -2 are elevated in human sepsis. Blood 1995, 86, 3841-3847. [CrossRef]

18. Yong, K.K.; Chang, J.H.; Chien, M.H.; Tsao, S.M.; Yu, M.C.; Bai, K.J.; Tsao, T.C.; Yang, S.F. Plasma monocyte chemoattractant protein-1 level as a predictor of the severity of community-acquired pneumonia. Int. J. Mol. Sci. 2016, 17, E179. [CrossRef]

19. Behjati, S.; Frank, M.H. The effects of tamoxifen on immunity. Curr. Med. Chem. 2009, 16, 3076-3080. [CrossRef]

20. Seli, E.; Pehlivan, T.; Selam, B.; Garcia-Velasco, J.A.; Arici, A. Estradiol down-regulates MCP-1 expression in human coronary artery endothelial cells. Fertil. Steril. 2002, 77, 542-547. [CrossRef]

21. Wang, L.; Zheng, W.; Zhang, S.; Chen, X.; Hornung, D. Expression of monocyte chemotactic protein-1 in human endometrial cancer cells and the effect of treatment with tamoxifen or buserelin. J. Int. Med. Res. 2006, 34, 284-290. [CrossRef]

22. Swirski, F.K.; Nahrendorf, M.; Etzrodt, M.; Wildgruber, M.; Cortez-Retamozo, V.; Panizzi, P.; Figueiredo, J.L.; Kohler, R.H.; Chudnovskiy, A.; Waterman, P.; et al. Identification of splenic reservoir monocytes and their deployment to inflammatory sites. Science 2009, 325, 612-616. [CrossRef]

23. Robbins, C.S.; Chudnovskiy, A.; Rauch, P.J.; Figueiredo, J.L.; Iwamoto, Y.; Gorbatov, R.; Etzrodt, M.; Weber, G.F.; Ueno, T.; van Rooijen, N.; et al. Extramedullary hematopoiesis generates Ly-6C(high) monocytes that infiltrate atherosclerotic lesions. Circulation 2012, 125, 364-374. [CrossRef]

24. Handel, T.M.; Johnson, Z.; Crown, S.E.; Lau, E.K.; Proudfoot, A.E. Regulation of protein function by glycosaminoglycans-as exemplified by chemokines. Annu. Rev. Biochem. 2005, 74, 385-410. [CrossRef]

25. Deshmane, S.L.; Kremlev, S.; Amini, S.; Sawaya, B.E. Monocyte chemoattractant protein-1 (MCP-1): An overview. J. Interferon Cytokine Res. 2009, 29, 313-326. [CrossRef] [PubMed]

26. Corriden, R.; Hollands, A.; Olson, J.; Derieux, J.; Lopez, J.; Chang, J.T.; Gonzalez, D.J.; Nizet, V. Tamoxifen augments the innate immune function of neutrophils through modulation of intracellular ceramide. Nat. Commun. 2015, 6, 8369. [CrossRef]

27. Yu, M.; Jiang, M.; Chen, Y.; Zhang, S.; Zhang, W.; Yang, X.; Li, X.; Li, Y.; Duan, S.; Han, J.; et al. Inhibition of macrophage CD36 expression and cellular oxidized low density lipoprotein (oxLDL) accumulation by tamoxifen: a peroxisome proliferator-activated receptor (PPAR)gamma-dependent mechanism. J. Biol. Chem. 2016, 291, 16977-16989. [CrossRef]

28. Miro-Canturri, A.; Ayerbe-Algaba, R.; Smani, Y. Drugs repurposing for the treatment of bacterial and fungal infections. Front. Microbiol. 2019, 10, 41. [CrossRef] [PubMed]

29. Ashburn, T.T.; Thor, K.B. Drug repositioning: identifying and developing new uses for existing drugs. Nat. Rev. Drug Discov. 2004, 3, 673-683. [CrossRef]

30. Chen, X.H.; Yin, Y.J.; Zhang, J.X. Sepsis and immune response. World J. Emerg. Med. 2011, 2, 88-92. [CrossRef] [PubMed]

31. Delano, M.J.; Ward, P.A. The immune system's role in sepsis progression, resolution and long-term outcome. Immunol. Rev. 2016, 274, 330-353. [CrossRef] [PubMed]

32. Serbina, N.V.; Hohl, T.M.; Cherny, M.; Pamer, E.G. Selective expansion of the monocytic lineage directed by bacterial infection. J. Immunol. 2009, 183, 1900-1910. [CrossRef]

33. Serbina, N.V.; Kuziel, W.; Flavell, R.; Akira, S.; Rollins, B.; Pamer, E.G. Sequential MyD88-independent and -dependent activation of innate immune responses to intracellular bacterial infection. Immunity 2003, 19, 891-901. [CrossRef]

34. Balamayooran, G.; Batra, S.; Balamayooran, T.; Cai, S.; Jeyaseelan, S. Monocyte chemoattractant protein 1 regulates pulmonary host defense via neutrophil recruitment during Escherichia coli infection. Infect. Immun. 2011, 79, 2567-2577. [CrossRef]

35. Jia, T.; Serbina, N.V.; Brandl, K.; Zhong, M.X.; Leiner, I.M.; Charo, I.F.; Pamer, E.G. Additive roles for MCP-1 and MCP-3 in CCR2-mediated recruitment of inflammatory monocytes during Listeria monocytogenes infection. J. Immunol. 2008, 180, 6846-6853. [CrossRef] [PubMed] 
36. Tsou, C.L.; Peters, W.; Si, Y.; Slaymaker, S.; Aslanian, A.M.; Weisberg, S.P.; Mack, M.; Charo, I.F. Critical roles for CCR2 and MCP-3 in monocyte mobilization from bone marrow and recruitment to inflammatory sites. J. Clin. Investig. 2007, 117, 902-909. [CrossRef] [PubMed]

37. Burdon, P.C.; Martin, C.; Rankin, S.M. The CXC chemokine MIP-2 stimulates neutrophil mobilization from the rat bone marrow in a CD49d-dependent manner. Blood 2005, 105, 2543-2548. [CrossRef]

38. Rankin, S.M. The bone marrow: a site of neutrophil clearance. J. Leuk. Biol. 2010, 88, 241-251. [CrossRef]

39. Dominguez, P.M.; Ardavin, C. Differentiation and function of mouse monocyte-derived dendritic cells in steady state and inflammation. Immunol. Rev. 2010, 234, 90-104. [CrossRef]

40. Serbina, N.V.; Salazar-Mather, T.P.; Biron, C.A.; Kuziel, W.A.; Pamer, E.G. TNF/iNOS-producing dendritic cells mediate innate immune defense against bacterial infection. Immunity 2003, 19, 59-70. [CrossRef]

41. Bosschaerts, T.; Guilliams, M.; Stijlemans, B.; Morias, Y.; Engel, D.; Tacke, F.; Hérin, M.; De Baetselier, P.; Beschin, A. Tip-DC development during parasitic infection is regulated by IL-10 and requires CCL2/CCR2, IFN-gamma and MyD88 signaling. PLoS Pathog. 2010, 6, e1001045. [CrossRef] [PubMed]

42. Nalbandian, G.; Paharkova-Vatchkova, V.; Mao, A.; Nale, S.; Kovats, S. The selective estrogen receptor modulators, tamoxifen and raloxifene, impair dendritic cell differentiation and activation. J. Immunol. 2005, 175, 2666-2675. [CrossRef] [PubMed]

43. Smani, Y.; Docobo-Pérez, F.; López-Rojas, R.; Domínguez-Herrera, J.; Ibáñez-Martínez, J.; Pachón, J. Platelet-activating factor receptor initiates contact of Acinetobacter baumannii expressing phosphorylcholine with host cells. J. Biol. Chem. 2012, 287, 26901-26910. [CrossRef] [PubMed]

44. Parra-Millán, R.; Guerrero-Gómez, D.; Ayerbe-Algaba, R.; Pachón-Ibáñez, M.E.; Miranda-Vizuete, A.; Pachón, J.; Smani, Y. Inracellular trafficking and persistence of Acinetobacter baumannii requires transcription factor EB. mSphere 2018, 3, e00106-18. [CrossRef] [PubMed]

45. Tomita, T.; Kanegasaki, S. Enhanced phagocytic response of macrophages to bacteria by physical impact caused by bacterial motility or centrifugation. Infect. Immun. 1982, 38, 865-870. [CrossRef]

46. Mittal, R.; Lisi, C.V.; Kumari, H.; Grati, M.; Blackwelder, P.; Yan, D.; Jain, C.; Mathee, K.; Weckwerth, P.H. Otopathogenic Pseudomonas aeruginosa enters and survives inside macrophages. Front. Microbiol. 2016, 7, 1828. [CrossRef]

47. Garai, P.; Berry, L.; Moussouni, M.; Bleves, S.; Blanc-Potard, A.B. Killing from the inside: Intracellular role of T3SS in the fate of Pseudomonas aeruginosa within macrophages revealed by mgtC and oprF mutants. PLoS Pathog. 2019, 15, e1007812. [CrossRef]

48. Corbun, J.; Frank, D.W. Macrophages and epithelial cells respond differently to the Pseudomonas aeruginosa type III secretion system. Infect. Immun. 1999, 67, 3151-3154.

49. Gil-Marqués, M.L.; Pachón-Ibáñez, M.E.; Pachón, J.; Smani, Y. Effect of hypoxia on the pathogenesis of Acinetobacter baumannii and Pseudomonas aeruginosa in vitro and in murine experimental models of infection. Infect. Immun. 2018, 86, e00543-18. [CrossRef] [PubMed]

50. Baumann, P.; Doudoroff, M.; Stanier, M.R. A 377 study of the Moraxella grouP. II. Oxidative negative species (genus Acinetobacter). J. Bacteriol. 1968, 95, 1520-1541. [CrossRef]

51. Holloway, I.W. Genetic recombination in Pseudomonas aeruginosa. J. Gen. Microbial. 1955, 13, 572-681. [CrossRef] [PubMed]

52. American Type Culture Collection (ATCC). Escherichia coli (Migula) Castellani and Chalmers (ATCC®25922 ${ }^{\mathrm{TM}}$ ); FDA strain Seattle [DSM 1103, NCIB 12210]; ATCC: Manassas, VA, USA, 1946.

53. Peña, C.; Suarez, C.; Gonzalo, M.; Murillas, J.; Almirante, B.; Pomar, V.; Aguilar, M.; Granados, A.; Calbo, E.; Rodríguez-Baño, J.; et al. Propsective muticenter study of the impact of carbapenem resistance on mortality in Pseudomonas aeruginosa bloodstream infections. Antimicrob. Agents Chemother. 2012, 56, 1265-1272. [CrossRef] [PubMed]

54. Algaba, R.A.; Álvarez-Marín, R.; Praena, J.; Smani, Y. Escherichia coli causing meningitis in an adult: A case report and experimental characterization of its virulence. Enferm. Infecc. Microbiol. Clin. 2019, 37, 418-419. [CrossRef] [PubMed]

55. Yanat, B.; Machuca, J.; Yahia, R.D.; Touati, A.; Pascual, Á.; Rodríguez-Martínez, J.M. First report of the plasmid-mediated colistin resistance gene mcr-1 in a clinical Escherichia coli isolate in Algeria. Int. J. Antimicrob. Agents 2016, 48, 760-761. [CrossRef]

56. Del Toro, R.; Chèvre, R.; Rodríguez, C.; Ordóñez, A.; Martínez-González, J.; Andrés, V.; Méndez-Ferrer, S. Nestin+ cells direct inflammatoy cell migration in atherosclerosis. Nat. Commun. 2016, 7, 12706. [CrossRef] [PubMed]

57. Dong, G.; Song, L.; Tian, C.; Wang, Y.; Miao, F.; Zheng, J.; Lu, C.; Alsadun, S.; Graves, D.T. FOXO1 regulates bacteria-induced neutrophil activity. Front. Immunol. 2017, 8, 1088. [CrossRef] 